\title{
Reply to the comment to the article "Open partial horizontal laryngectomies: a proposal for classification by the working committee on nomenclature of the European Laryngological Society"
}

\author{
Giovanni Succo · Giorgio Peretti · Cesare Piazza
}

Received: 21 July 2014/ Accepted: 29 July 2014/Published online: 17 August 2014

(C) Springer-Verlag Berlin Heidelberg 2014

We wish to thank Dr. Wierzbicka for the interesting comments to the paper "Open partial horizontal laryngectomies: a proposal for classification by the working committee on nomenclature of the European Laryngological Society" by Succo et al. [1]. Its declared aim, as well as that of the other ELS classifications on oncologic subjects published in the past years [2-4] is to create a common platform for sharing surgical data among the greatest number of institutions worldwide. In this sense, the specific intent of our working committee was to keep the classification as easy as possible, including only well-known, standardized, and widely accepted procedures, reproducible among the entire head and neck surgical community. Clearly, this is required to make choices among the dozens of types of open partial laryngectomies described in the literature, focusing on those that, in our opinion, still play a pivotal role between the two extremes of transoral microsurgery on one hand, and total laryngectomy on the other. Among the many less common types of open partial laryngectomies, horizontal glottectomy, described in 1978 by Calearo and Teatini [5] (who were both, by the way,

This reply refers to the comment available at doi:10.1007/s00405-014-3222-0.

\section{G. Succo}

Department of Otorhinolaryngology, Ospedale San Luigi and Ospedale Martini, University of Turin, Turin, Italy

\section{G. Peretti}

Department of Otorhinolaryngology, Ospedale San Martino, University of Genoa, Genoa, Italy

\section{Piazza ( $\square)$}

Department of Otorhinolaryngology, Head and Neck Surgery, Spedali Civili of Brescia, University of Brescia, Piazza Spedali Civili 1, 25123 Brescia, Italy

e-mail: ceceplaza@libero.it strictly linked to our laryngological school), definitely represents a procedure that is nowadays quite limited in its application since it has been overshadowed, for the reported indications, by transoral laser microsurgery and radiotherapy. Nevertheless, we are perfectly aware of the fact that any classification of surgical procedures should be regarded as a temporary tool that is being continuously reshaped and modified whenever consistent limits in its application should become evident in the future among the head and neck cancer community.

Conflict of interest None.

\section{References}

1. Succo G, Peretti G, Piazza C, Remacle M, Eckel HE, Chevalier D, Simo R, Hantzakos AG, Rizzotto G, Lucioni M, Crosetti E, Antonelli AR (2014) Open partial horizontal laryngectomies: a proposal for classification by the working committee on nomenclature of the European Laryngological Society. Eur Arch Otorhinolaryngol 271(9):2489-2496

2. Remacle M, Eckel HE, Antonelli A, Brasnu D, Chevalier D, Friedrich G, Olofsson J, Rudert HH, Thumfart W, de Vincentiis M, Wustrow TP (2000) Endoscopic cordectomy. A proposal for a classification by the Working Committee, European Laryngological Society. Eur Arch Otorhinolaryngol 257(4):227-231

3. Remacle M, Van Haverbeke C, Eckel H, Bradley P, Chevalier D, Djukic V, de Vincentiis M, Friedrich G, Olofsson J, Peretti G, Quer M, Werner J (2007) Proposal for revision of the European Laryngological Society classification of endoscopic cordectomies. Eur Arch Otorhinolaryngol 264(5):499-504

4. Remacle M, Hantzakos A, Eckel H, Evrard AS, Bradley PJ, Chevalier D, Djukic V, de Vincentiis M, Friedrich G, Olofsson J, Peretti G, Quer M, Werner J (2009) Endoscopic supraglottic laryngectomy: a proposal for a classification by the working committee on nomenclature, European Laryngological Society. Eur Arch Otorhinolaryngol 266(7):993-998

5. Calearo CV, Teatini G (1978) Horizontal glottectomy. Laryngoscope 88(9):1529-1535 